\title{
THE EFFECT OF BLOOD PRESSURE ALTERATION ON THE PULSE WAVE VELOCITY
}

\author{
BY \\ E. R. NYE \\ From the Wellcome Research Institute, Dunedin, New Zealand \\ Received January 21, 1963
}

Determinations of the pulse wave velocity (PWV) in living subjects have shown that higher values are found with increasing age (Rahier, 1961; Simonson and Nakagawa, 1960) and in the presence of hypertension, with or without presumed atherosclerosis, but more so in the former case (Miasnikov, 1960). Woolam et al. (1962) have also shown higher values in diabetics with presumed atherosclerosis, compared with normal subjects.

Comparison of PWV values obtained by different workers is difficult because of the variable techniques employed and different criteria used in estimating the length of the vessel over which the recordings were made; in addition not all workers have used the same vessels for their measurements, or the same events in the cardiac cycle for timing purposes. It may be assumed further that recordings are usually carried out with the patient in the supine position but this is not always specified.

Attention to these points is essential in considering what importance to attach to differences in figures given by various authors in reported PWV measurements. It is noted for example that the "normal" values quoted by Miasnikov are lower than those of Rahier's series by almost two metres per second for subjects in their third decade. The values of PWV measured in peripheral vessels are higher than corresponding measurements in the aorta. This is consistent with the Moens-Korteweg. equation (Moens, 1878; Korteweg, 1878), which is as follows:

$$
\mathrm{PWV}=\sqrt{\frac{\mathrm{E.h}}{2 \rho^{\prime} \mathrm{r}}}
$$

where $E$ is the transverse elasticity coefficient, $h$ is the thickness of vessel wall, $r$ is the radius of the vessel and $\rho$ ' is the density of fluid. In terms of this equation, and other values being constant, PWV is inversely proportional to the square root of the vessel radius.

With the present recording methods accurate measurement of the very small delays between the arrival of the pulse wave at different points along a short vessel is not easy, even if the complicating effects of wave reflections from arterial branchings are ignored (McDonald, 1960).

Hitherto little or no documentation concerning the effect of induced blood pressure alterations in the living subject on the PWV has appeared although it is generally agreed that the PWV is directly proportional to the level of blood pressure, albeit in terms of a non-linear relation: the experimental studies on living dogs and isolated aortæ from these animals by Hamilton, Remington, and Dow (1945) support this view.

The above considerations prompted this study into the magnitude of the contribution to the PWV made by the blood pressure in living subjects.

\section{METHOD}

Pulse wave recording was carried out using diaphragm-operated crystal microphones each coupled to a D.C. cathode follower through an amplifier unit limited to an upper response of 20 c.p.s. Simultaneous 


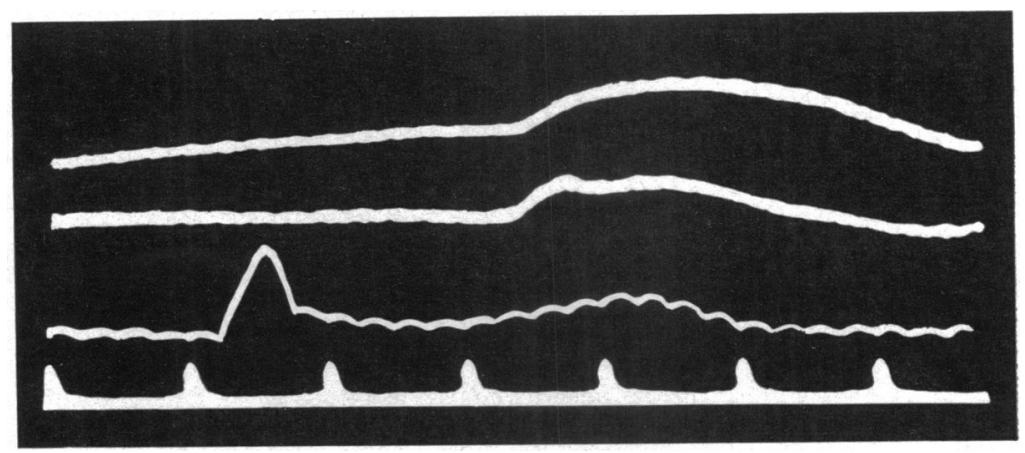

FIG. 1.-Representative recording showing $0.08 \mathrm{sec}$. time marker (lower trace), cardiogram trace (above time marker trace) and pulse waves at femoral point (upper two traces).

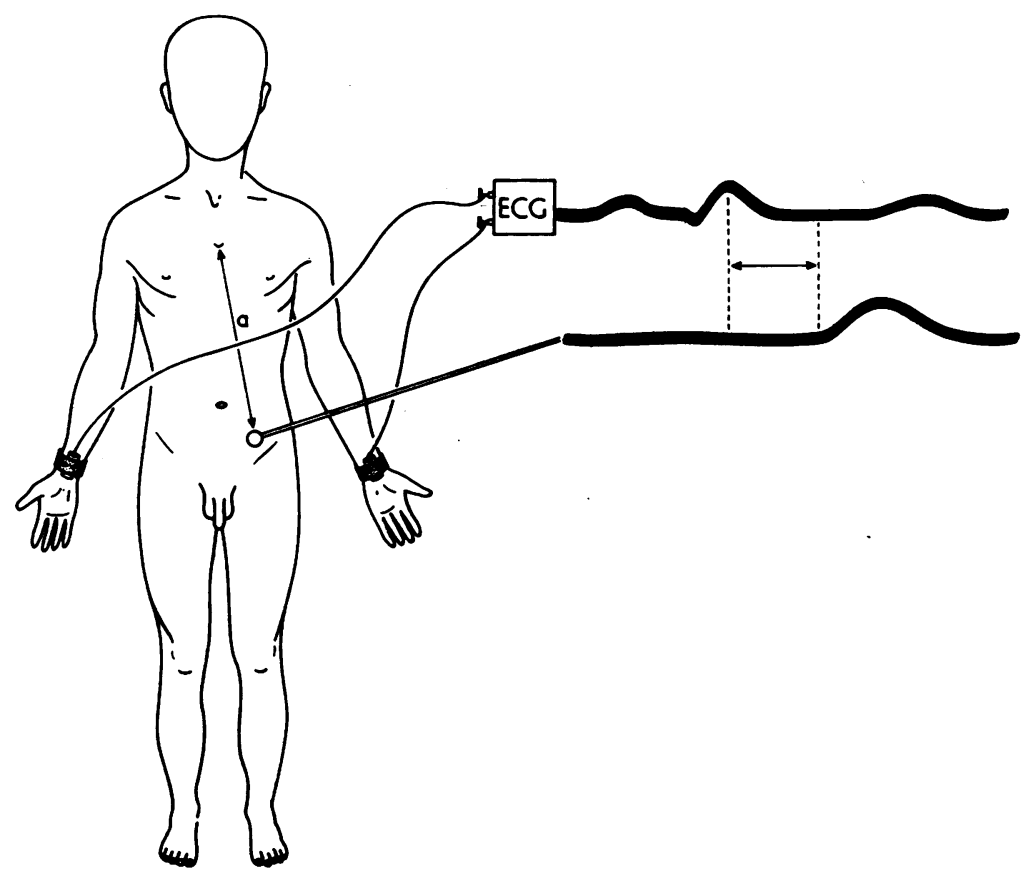

FIG. 2.-Distance " $a$ " represents distance measured between manubrio-sternal joint and position of the microphone over the femoral artery. The interval between $R$ wave peak and foot point of the pulse wave is also shown.

recording was made also of the electrocardiograph trace using a conventional electrocardiograph amplifier. A fourth channel recorded an 80-millisecond time signal obtained by squaring and scaling the 50 c.p.s. mains frequency. This saw-tooth sweep is a linearized D.C. coupled bootstrap circuit driving a D.C. deflection amplifier. The four traces were swept out at four consecutive positions on a long persistence cathode ray screen for visual or photographic purposes as required.

A pair of microphones was used, recording from both femoral arteries just below the inguinal ligament, and held in place by a broad elastic bandage. Photographic recording of the traces so obtained allowed subsequent enlargement (Fig. 1). It is estimated that the final readings were accurate to within 5 milliseconds. An estimate of the length of the arterial segment under study was obtained by measuring the distance between the manubrio-sternal junction and the point on the femoral artery at which the recording was made over the 
skin surface (Fig. 2). In fact the above measurement falls short of the actual intra-arterial distance, as measured in cadavers, by a factor of approximately 0.79 . It was not felt that the more elaborate manœuvres designed to measure the length of vessel under examination were free from the objection of possessing an implied accuracy inherently unobtainable. In any event the purpose of the present investigation was not to establish absolute values for pulse wave velocity. It is clear, however, that the body stature must be taken into account in studies of this nature, and the above measurement filled the need for a correction factor.

Calculation of the PWV was made by taking the distance between the manubrio-sternal junction and the femoral microphone and dividing this by the time interval, in seconds, between the $\mathbf{R}$ wave peak of the cardiogram trace and the foot-points of the pulse waves as recorded at the femoral points. The "foot point" of the pulse trace was defined as the intersection point of two lines, one drawn along the lower margin of the trace and across the take-off point and the other along the lower margin of the rising slope at the take-off point. The photographic recording was magnified $\times 10$ on a screen for this purpose. As far as possible 10 measurements were made for every final PWV value obtained. In some cases fewer than 10 traces were suitable for measurement and in these circumstances not less than 5 measurements were accepted. In this way the error introduced by variability in the PWV, which occurs from trace to trace, was reduced.

Blood-pressure recordings were made at intervals during the course of investigations using a conventional sphygmomanometer on the brachial artery. Comparison of readings so made with those recorded from a catheter in the aorta connected to a Statham strain gauge coupled to a Sanborn direct writing instrument showed that systolic pressures tended to be underestimated in the arm and diastolic pressures overestimated.

In a number of experiments the pulse rate was determined using a conventional electrocardiograph machine.

In two groups of subjects (one consisting of 5 normal persons and the other of 5 patients with hypertension) alteration of the blood pressure was achieved by the administration of drugs intravenously using continuous infusion of physiological saline as the vehicle. Reduction of pressure was achieved in all cases using hexamethonium bromide, and increase of pressure using metaraminol $(0.1 \mathrm{mg} . / \mathrm{ml}$.). Subjects were asked to report any subjective sensation they experienced but as far as possible they were given no indication when administration of the active agent was started. All experiments were conducted about two hours after the last meal and no recording was made until the subject was accustomed to the surroundings and a steady level of blood pressure had been obtained. In all cases the subject was placed on a padded couch in a $30^{\circ}$ head-up position, thus allowing a fall of pressure following administration of hexamethonium.

\section{RESUlts}

Normal Subjects. These five subjects were normal persons, colleagues, or other volunteers with no overt evidence of cardiovascular disease. A representative result obtained in one subject (R.G.) is shown in Fig. 3.

Hypertensive Subjects. Five subjects were drawn from patients attending the hypertensive clinic attached to the Wellcome Research Institute and included one subject with known cerebral vascular disease and intermittent claudication (H.M.) and one with hypertensive heart disease but without cardiographic evidence of myocardial ischæmia (J.B.H.). A representative result, from the hypertensive patient R.G.B., is shown in Fig. 4.

The Table summarizes the maximum and minimum blood pressure values achieved and shows the corresponding PWV values.

\section{DisCUSSION}

These experiments confirm the findings of previous authors (Beyerholm, 1927; Hallock, 1934; Miasnikov, 1960; Rahier, 1961) that the PWV is found at a higher level in the presence of hypertension with or without evidence of atherosclerosis. Some authors appear to have neglected the blood-pressure factor, for example Hasik and Gottschalk (1958).

Little or no work has been reported dealing with the alteration in PWV that may be obtained in the same subject by induced changes of the blood pressure. It is appreciated that many parameters affect the magnitude of the PWV, some of which are included in the Moens-Korteweg equation. These factors are either not measurable, or only so with difficulty in the living subject, and tend to be neglected by students of PWV. The assumption usually made is that the transverse elasticity 


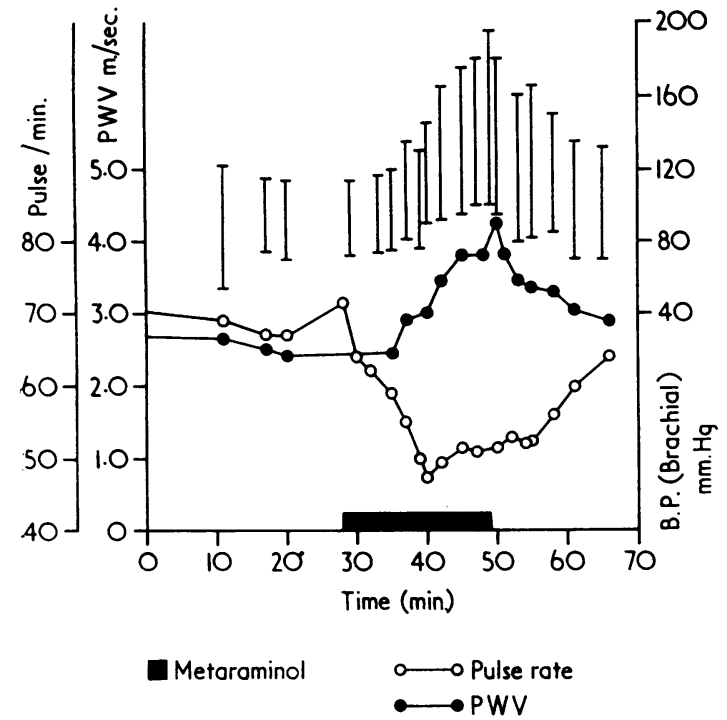

FIG. 3.-Subject R.G. with normal blood pressure showing effect of raising the blood pressure on the pulse wave velocity using intravenous metaraminol. The subject was in a $30^{\circ}$ head-up position.

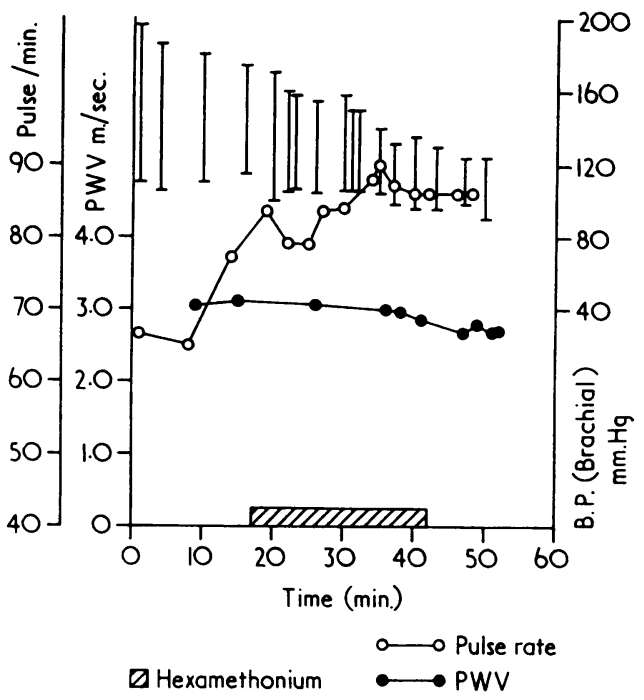

FIG. 4.-Patient R.G.B. with hypertension showing effect of blood pressure reduction on the pulse wave velocity using intravenous hexamethonium with the patient in a $30^{\circ}$ head-up position.

coefficient of the vessel wall (E) is the main determinant. The present work shows clearly the extent to which PWV may be altered in the same subject by blood pressure alteration, granted always that while some factors, such as blood viscosity, are not altered, others, such as cardiac output, may be.

Of interest was the finding of a greater augmentation of the PWV in the normal subject under conditions of induced pressure increase as compared with the hypertensive subject, even though the mean pressures of the two groups were closely similar at that time. It is noted also that the overall

TABLE

Patients with Hypertension and Control Subjects with Maximum and Minimum Blood Pressure Levels and Corresponding Pulse Wave Velocity Values

\begin{tabular}{|c|c|c|c|c|c|c|c|c|c|}
\hline Subjects & & $\begin{array}{l}\text { Age } \\
\text { (yr.) }\end{array}$ & Sex & $\begin{array}{c}\text { Maximum } \\
\text { blood pressure } \\
(\mathrm{mm} . \mathrm{Hg})\end{array}$ & $\begin{array}{l}\text { Corres- } \\
\text { ponding } \\
\text { PWV } \\
(\mathrm{m} . / \mathrm{sec} .)\end{array}$ & $\begin{array}{l}\text { Minimum } \\
\text { blood pressure } \\
(\mathrm{mm} . \mathrm{Hg})\end{array}$ & $\begin{array}{l}\text { Corres- } \\
\text { ponding } \\
\text { PWV } \\
\text { (m./sec.) }\end{array}$ & $\begin{array}{c}\text { Fall in } \\
\text { diastolic } \\
\text { blood } \\
\text { pressure } \\
(\mathrm{mm} . \mathrm{Hg})\end{array}$ & $\begin{array}{c}\text { PWV } \\
\text { fall } \\
\text { (m./sec.) }\end{array}$ \\
\hline $\begin{array}{l}\text { Hypertension } \\
\text { R.G.B. } \\
\text { D.H.B. } \\
\text { A.C.H. } \\
\text { J.B.H. } \\
\text { H.M. . . } \\
\text { Mean . . }\end{array}$ & $\begin{array}{l}\ldots \\
\ldots \\
\ldots \\
\ldots \\
\ldots \\
\ldots\end{array}$ & $\begin{array}{l}39 \\
44 \\
52 \\
54 \\
60 \\
-\end{array}$ & $\begin{array}{l}\mathbf{F} \\
\mathbf{M} \\
\mathbf{M} \\
\mathbf{M} \\
\mathbf{M} \\
\end{array}$ & $\begin{array}{l}190 / 110 \\
164 / 134 \\
210 / 130 \\
168 / 125 \\
210 / 125 \\
186 / 125\end{array}$ & $\begin{array}{l}3 \cdot 04 \\
3 \cdot 86 \\
3 \cdot 82 \\
3 \cdot 91 \\
4 \cdot 33 \\
3 \cdot 79\end{array}$ & $\begin{array}{l}124 / 90 \\
134 / 116 \\
140 / 105 \\
105 / 85 \\
165 / 118 \\
134 / 103\end{array}$ & $\begin{array}{l}2.67 \\
3.13 \\
3.09 \\
2.97 \\
3.56 \\
3.08\end{array}$ & $\begin{array}{r}20 \\
18 \\
25 \\
40 \\
7 \\
22\end{array}$ & $\begin{array}{l}0.37 \\
0.73 \\
0.73 \\
0.94 \\
0.77 \\
0.71\end{array}$ \\
\hline $\begin{array}{c}\text { Normal } \\
\text { R.G. . } \\
\text { J.M. . } \\
\text { T.W. ․ } \\
\text { W.J.H. } \\
\text { R.F.P. } \\
\text { Mean . . }\end{array}$ & $\begin{array}{l}\ldots \\
\ldots \\
\ldots \\
\ldots \\
\ldots\end{array}$ & $\begin{array}{l}21 \\
29 \\
30 \\
40 \\
53 \\
-\end{array}$ & $\begin{array}{l}\mathbf{M} \\
\mathbf{M} \\
\mathbf{M} \\
\mathbf{M} \\
\mathbf{M} \\
\end{array}$ & $\begin{array}{l}195 / 100 \\
195 / 110 \\
190 / 128 \\
160 / 105 \\
170 / 115 \\
182 / 111\end{array}$ & $\begin{array}{l}4 \cdot 24 \\
5 \cdot 31 \\
4 \cdot 27 \\
4 \cdot 00 \\
4 \cdot 26 \\
4 \cdot 41\end{array}$ & $\begin{array}{r}114 / 70 \\
85 / 65 \\
115 / 95 \\
120 / 92 \\
122 / 90 \\
111 / 82\end{array}$ & $\begin{array}{l}2 \cdot 43 \\
2 \cdot 04 \\
3 \cdot 08 \\
2 \cdot 96 \\
3 \cdot 11 \\
2 \cdot 72\end{array}$ & $\begin{array}{l}30 \\
45 \\
33 \\
13 \\
25 \\
29\end{array}$ & $\begin{array}{l}1 \cdot 81 \\
3 \cdot 27 \\
1 \cdot 19 \\
1.04 \\
1 \cdot 15 \\
1 \cdot 69\end{array}$ \\
\hline
\end{tabular}


induced changes of PWV are greater in the normal subjects than in the hypertensive subjects; the mean change in the normal and hypertensive subjects being 62 per cent and 23 per cent respectively, relative to the lowest PWV obtained in each group.

It seems that in hypertension the PWV may be less pressure dependent than in normal subjects. McDonald (1960) notes that the elastic modulus of an isolated artery increases as the tension increases, and on general grounds it seems likely that this capacity for change decreases as degenerative processes advance in an artery; to take an extreme example, the heavily calcified "pipe-stem" artery of advanced atherosclerosis would have a high but relatively fixed elastic modulus.

The present work shows clearly the change in PWV, as measured from the heart to the femoral artery, that occurs in one and the same subject when the pressure is increased in the case of normal subjects, or decreased in the case of patients with hypertension. While such changes are not the result of permanent alteration in the blood vessels, the results suggest that the magnitude of such changes may be.

\section{SummaRY AND CONCLUSIONS}

Experiments were carried out on five subjects with hypertension and five normal subjects in whom changes in blood pressure were induced by pharmacological means. It was found that the pulse wave velocity in the aorta and iliac arteries suffered greater alteration in the normal subjects as a result of increase of blood pressure than did that of the subjects with hypertension who suffered an induced fall of pressure. At high pressure levels, closely comparable in the two groups, the subjects with normal blood pressure had higher pulse wave velocity values than the subjects with hypertension. At the low pressure range the subjects with hypertension had a higher pulse wave velocity than the normal subjects but the blood pressure of the former group was somewhat higher.

The results suggest a greater capacity for change in the elastic modulus of the arteries of the subjects with normal blood pressure, as compared to the subjects with hypertension, in keeping with the probability of a higher incidence of degenerative changes in the arteries of the latter.

It is a pleasure to be able to thank Sir Horace Smirk for his criticism and suggestions and Mr. A. T. Wallis who built the recording apparatus in the Institute's workshops. The work was supported by the Medical Research Council of New Zealand.

\section{REFERENCES}

Beyerholm, O. (1927). Studies of the velocity of transmission of the pulse wave in different pathological conditions (principally arteriosclerosis with and without hypertonia and heart-arythmiæ). Acta. med. scand., 67, 323.

Hallock, P. (1934). Arterial elasticity in man in relation to age as evaluated by the pulse wave velocity method. Arch. intern. Med., 54, 770.

Hamilton, W. F., Remington, J. W., and Dow, P. (1945). The determination of the propagation velocity of the arterial pulse wave. Amer. J. Physiol., 144, 521.

Hasik, J., and Gottschalk, W. (1958). Pomiary szybkosci rozchodzenia sie fali tetna za pomoca elektrokardiogramu oraz pletyzmogramu palcowego. Pol. Arch. Med. wewnęt., 28, 738.

Korteweg, D. J. (1878). Uber die Fortpflanzungsgeschwindigkeit des Schalles in elastischen Rohren. Ann. Phys., Lpz. Neue Folge, 5, 525.

McDonald, D. A. (1960). Blood Flow in Arteries. (Physiol. Soc. Monogr. No. 7). London.

Miasnikov, A. L. (1960). Diagnostic and pathogenic borderlines between hypertensive disease and atherosclerosis. Amer. J. Cardiol., 5, 692.

Moens, A. I. (1878). Die Pulskurve. Brill, Leiden.

Rahier, J. P. (1961). Étude de la vitesse de l'onde sphygmique dans l'aorte. Ses variations au cours de l'artériosclérose. Acta cardiol. (Brux.), 16, 425.

Simonson, E., and Nakagawa, K. (1960). Effect of age on pulse wave velocity and "aortic ejection time" in healthy men and in men with coronary artery disease. Circulation, 22, 126.

Woolam, G. L., Schnur, P. L., Vallbona, C., and Hoff, H. E. (1962). The pulse wave velocity as an early indicator of atherosclerosis in diabetic subjects. Circulation, 25, 533. 